\title{
A molten Mg corrosion method for preparing porous Ti foam as self-supported
}

\section{$\mathrm{Li}-\mathrm{O}_{2}$ battery cathodes}

Guangyu Zhao, Li Zhang, Yanning Niu and Kening Sun*

\begin{abstract}
All-metal self-supported cathodes, especially porous noble metals, are attractive alternatives for settling the issue of carbon- and binder-decomposition in $\mathrm{Li}-\mathrm{O}_{2}$ batteries. However, the high cost of noble metals hinders their practical application. In the present study, nanoporous $\mathrm{Ti}$ foam is prepared using a molten $\mathrm{Mg}$ corrosion method for the first time. Electron microscope images demonstrate that, nanoporous Ti foam is obtained by treating Ti-Mo alloy plates in molten $\mathrm{Mg}$ at $650{ }^{\circ} \mathrm{C}$ for 3 hours. Then, the foam is coated with a layer of Au nanoparticles by cool-sputtering and used as self-supported $\mathrm{Li}-\mathrm{O}_{2}$ battery cathodes. The nanoporous foam can decrease the consumption of gold markedly compared with traditional porous Au foam. Benefiting from the high stability, conductivity, and porosity of $\mathrm{Ti}$ foam, the $\mathrm{Li}-\mathrm{O}_{2}$ batteries exhibit good durability (cycling 118 rounds at $1 \mathrm{C}$ rate within a $1000 \mathrm{mAh} \mathrm{g}^{-1}$ capacity limitation).
\end{abstract}

Keywords: Li oxygen battery; Cathode; Porous Ti; Molten Mg corrosion 
Porous metal foam is widely used in various areas, such as catalysts and catalyst supports, water purification, and current collectors of energy storage and conversion devices [1]. Generally, the most widely used materials of metal foam are $\mathrm{Au}, \mathrm{Ag}, \mathrm{Ni}$, $\mathrm{Al}$, and $\mathrm{Cu}$, etc. Common methods to prepare porous metals include sintering metal powders, replication of polymeric sponge, freeze casting, and de-alloy [1]. However, few porous metals have a tough and self-supported nanoporous structure because of the intrinsic properties of the metals or the limitation of manufacturing methods [1-8]. The nanoporous metals have large surface area and abundant inner space to accommodate active materials as catalyst supports and current collectors [2,3]. Unfortunately, nanoporous metals usually have not tough structures for using as self-supported electrodes, which is unfavorable for the stability and durability as using them in energy storage and conversion devices [9-13].

Ti and its alloys have been widely used for dental and orthopedic implants, owing to their good chemical stability, mechanical properties and biocompatibility $[14,15]$. Recently, Ti and its alloys in the form of porous structure have attracted increasing interest as current collectors or catalyst supports (e.g. in $\mathrm{Li}-\mathrm{O}_{2}$ batteries (LOBs) and fuel cells), because they can provide not only a favorable channel net for mass transport but also stable surface to prevent side reactions $[16,17]$. Chemical/electrochemical corrosion of some species with high oxidizing ability in operation environment of these devices limits the materials of current collectors in several alternatives [18-19], in which, Ti is the most attractive owing to its low cost 
compared with precious metals and high stability compared with $\mathrm{Ni}, \mathrm{Al}$, and $\mathrm{Cu}$ etc [16,17]. Although several methods were proposed to prepare porous Ti foam, the nanoporous structures were reported sparsely. Herein, we use a molten $\mathrm{Mg}$ corrosion method to prepare porous Ti foam, and the electrochemical properties of LOBs when using the porous Ti foams as current collectors are measured. It is worth noting that using molten $\mathrm{Mg}$ corrosion to prepare porous $\mathrm{Ti}$ is reported firstly to the best of our knowledge.

\section{Experimental}

Sample Preparation: Porous Ti foam were prepared on circular Ti alloy plates (Ti-Mo alloy, Mo=0.3 wt $\%, 15 \mathrm{~mm}$ diameter, $0.5 \mathrm{~mm}$ thickness) purchased from Baiji Jinkai Corporation of China. The raw Ti plate was buried with Mg powder (Alladin Com. China) in a crucible and heat-treated in Ar atmosphere for several hours. Then the Ti plate was immersed in $1 \mathrm{~mol} \mathrm{dm}^{-3} \mathrm{HCl}$ solution $24 \mathrm{~h}$ to remove metal $\mathrm{Mg}$ and magnesium oxide. The obtained porous Ti foam was rinsed with deionized water fully and dried overnight. Au nanoparticles were deposited on the Ti foam by a Leica EM SC050 cool-sputtering device at a current of $20 \mathrm{~mA}$ for $80 \mathrm{~s}$. Weights of the deposits were measured by means of a micro-balance (Mettler Toledo, USA) with an accuracy of $0.01 \mathrm{mg}$. The mass of Au nanoparticles was around $1.0 \mathrm{mg} \mathrm{cm}^{-2}$. The Au coating amount corresponds to the geometric surface of Ti supports (15mm diameter plates), and the total amount of $\mathrm{Au}$ is $1.76 \mathrm{mg}$.

Instruments for Characterization: Scanning electron microscope (SEM) images were obtained on a Hitachi Su-8100. The X-ray diffraction (XRD) patterns were obtained 
on a PANalytical X'pert PRO X-ray diffractometer with $\mathrm{Cu} \mathrm{K} \alpha$ radiation $(\lambda=1.5418$ A). Transmission electron microscope (TEM) images and selected area electro diffraction (SAED) patterns were obtained on a JEOL-2100. X-ray photoelectron spectra (XPS) were obtained with a K-Alpha electron spectrometer (Thermofish Scientific Company) using $\mathrm{Al} \mathrm{K} \alpha(1486.6 \mathrm{eV})$ radiation. The base pressure was about $1 \times 10^{-8}$ mbar. The binding energies were referenced to the $\mathrm{C} 1 \mathrm{~s}$ line at $284.8 \mathrm{eV}$ from adventitious carbon. The surface area of the materials was analyzed by the Brunauer-Emmett-Teller (BET) method with a Micromeritics Accelerated Surface Area and Porosimetry System (ASAP) 2020. The gas used was $\mathrm{N}_{2}$ with a liquefaction temperature of $-195.87{ }^{\circ} \mathrm{C}$, and the gas desorption time was $6 \mathrm{~h}$. The total pore volume and pore size distribution were evaluated by the Density functional theory (DFT) model. The cyclic voltammetry (CV) and electrochemical impedance spectroscopy (EIS) tests of the batteries were carried out on a CHI 660 electrochemical workstation.

$\mathrm{Li}-\mathrm{O}_{2}$ battery tests: The $\mathrm{Swagelok}$ type $\mathrm{Li}-\mathrm{O}_{2}$ batteries were assembled inside an MBraun glove box. The cells were constructed by placing a $15 \mathrm{~mm}$ diameter Li disk on the bottom, covering it with a piece of glass fiber separator $(20 \mathrm{~mm}$ diameter, Whatman), adding excess electrolyte $\left(1.0 \mathrm{~mol} \mathrm{dm}^{-3}\right.$ LiTFSI in tetraethylene glycol dimethyl ether (TEGDME)), placing a Au nanoparticle modified porous Ti foam disk (15 $\mathrm{mm}$ diameter) on the separator, and sealing the Swagelok cell. All the electrochemical measurements to the batteries were carried out in pure $\mathrm{O}_{2}$ at $1 \mathrm{~atm}$ 
(99.99\%). A BTS-2000 Neware Battery Testing System was employed for charge/discharge tests.

3. Results and discussion

In industrial process, the raw $\mathrm{Ti}$ foam plates are manufactured by pressing sintered Ti particles, and they are usually used as catalyst supports or water filters [16]. SEM images of a raw Ti-Mo alloy plate are shown in Fig. S1a. The higher amplification image in inset of Fig. S1a demonstrates smooth surface of the raw Ti alloy plate. For the application in water filtration or catalyst supports, the addition of Mo in Ti alloy plates is a common strategy to improve heat resistance and mechanical strength. However, Mo peaks are undetected in the XRD pattern of raw plates due to the low content, as shown in Fig. 1. The pattern of raw Ti plates can be assigned to Ti metal (JCPDS: 65-9622 $a=2.951, b=2.951, c=4.686$ ). Fig. S1b shows SEM image of the plate heat-treated in $\mathrm{Mg}$ for $3 \mathrm{~h}$. The surface becomes rough compared with the raw sample visibly resulted from the covering of Mg. XRD pattern of the plate treated with molten $\mathrm{Mg}$ verified that, the rough cover is Mg metal (JCPDS: 65-3365 $a=3.209$, $b=3.209, c=5.210$ and 65-7219 $a=2.953, b=2.953, c=2.953)$. After dissolving the cover with hydrochloric acid fully, the surface morphology is notably different compared with raw samples, as shown in the SEM images in Fig. 2. Moreover, the samples treated with $\mathrm{Mg}$ at different temperatures exhibit visibly different morphology. Pores with size of hundreds nanometers generate when the temperature over $650{ }^{\circ} \mathrm{C}$ (Fig. 2b), and the pores collapse at $750{ }^{\circ} \mathrm{C}$ (Fig. 2c), even vanish at 800 ${ }^{\circ} \mathrm{C}$ (Fig. 2d). There is no pore on the sample obtained at $550{ }^{\circ} \mathrm{C}$ (Fig. 2a) because of 
the lower temperature than Mg's fusion point. Accordingly, we consider the pores generating from molten $\mathrm{Mg}$ corrosion [21]. Specially, widespread and deep pores can be found in the samples obtained from $650{ }^{\circ} \mathrm{C}$, as shown in Fig. 2e and $\mathrm{f}$. The XRD pattern of the sample after dissolving off $\mathrm{Mg}$ ("Porous Ti foam" in Fig. 1) reveals the porous framework comprising $\mathrm{Ti}$ (JCPDS: 65-9622) and Mo (JCPDS: 65-7442 $a=3.147, b=3.147, c=3.147)$ metals. The clearer Mo peaks indicate the remaining framework contains more Mo metal than raw samples.

\section{Fig. 1.}

\section{Fig. 2.}

\section{Scheme 1.}

We suggest the formation process of pores in Ti foam can be described by the schematic diagram in Scheme 1. Mo element can penetrate into Ti powder along with grain boundaries, and forms alloy with $\mathrm{Ti}$ on the boundaries in manufacturing process of Ti alloy plates as we know. Mo is a high fusion point metal making it hard to be corroded by molten Mg [21]. The Ti-Mo alloy on the boundaries remains, while the $\mathrm{Ti}$ in grains is corroded by molten $\mathrm{Mg}$, resulting in a porous structure after removing Mg. This hypothesis can be verified by investigating the pore walls of as-prepared samples. HRTEM images and SAED patterns of the pore walls scraped from the as-prepared samples at $650{ }^{\circ} \mathrm{C}$ (Fig. 2b, e and f) demonstrate a Ti-Mo alloy comprising Ti and Mo nanocrystals, as shown in Fig. 3. HRTEM images of selected areas from Fig. 3a are shown in Fig. 3b and c, which can be assigned to Ti (002) and Mo (110) planes, respectively. Furthermore, SAED patterns of the walls in inset of 
Fig. 3a reflect the coexistence of Ti and Mo nanocrystals in the walls. To reveal the role of Mo in pores forming, comparative experiments were carried out on pure $\mathrm{Ti}$ foils (99\%, Alfa Aesar). SEM image of pure Ti foil after molten Mg corrosion in Fig. S2 shows no pores generating on the foil. Accordingly, we suggest the molten $\mathrm{Mg}$ corrosion leads pores forming in Ti-Mo alloy plates, and the pore structures depend on heat-treating temperature seriously because of higher corrosion ability of $\mathrm{Mg}$ at higher temperatures [21], as shown in the SEM images (Fig. 2c and d). Another factor deciding the structures of $\mathrm{Ti}$ foam is the heat-treating time, as seen from the plates treated at $650{ }^{\circ} \mathrm{C}$ with different times in Fig. 4. Apparently, the pore size increases with the corrosion time. Pores of the sample treated for $6 \mathrm{~h}$ are larger than those with shorter times. Meanwhile, the pore walls are corroded to be thinner with the treating time increasing. Nevertheless, the walls collapse as the time rising to $12 \mathrm{~h}$. The variation of the samples' morphology with treating times can also support the proposed mechanism above. The molten $\mathrm{Mg}$ can corrode $\mathrm{Ti}$ metal at high temperatures, but the grain boundaries remain owing to its alloying with Mo. Similarly with the situation at high temperature, the grain boundaries collapses due to the excessive corrosion as the treating time over $12 \mathrm{~h}$.

\section{Fig. 3.}

\section{Fig. 4.}

\section{Fig. 5.}

The $\mathrm{N}_{2}$ adsorption/desorption measurements were carried out on raw $\mathrm{Ti}$ plates and nanoporous $\mathrm{Ti}$ foam obtained from $650{ }^{\circ} \mathrm{C}$ with $6 \mathrm{~h}$. As shown in Table S1, the 
BET surface area and pore volume were enlarged over 5 and 40 times, respectively, after molten $\mathrm{Mg}$ corrosion. The adsorption/desorption isotherms and pore distribution curves of the two samples are presented in Fig. 5. After corrosion, the Ti foam possesses plentiful pores in size of 10-100 nm (Fig. 5d) leading the isotherm appearing a hysteretic loop (Fig. 5b) identified as type-IV isotherm. This suggests the existence of mesopores in the sample besides the primary macropores. Contrarily, raw Ti plate has not pores in this range, revealed from whether isotherm (Fig. 5a) or pore distribution curve (Fig. 5c). Therefore, the obtained $\mathrm{Ti}$ plate possesses not only macropores that in size of hundreds $\mathrm{nm}$, but also abundant nanopores in size of $10-100 \mathrm{~nm}$

\section{Fig. 6.}

The abundant pores in size of a wide range are attractive to electrochemical energy storage devices. Herein, we have investigated electrochemical properties of the porous foam as self-supported LOB cathodes, whose performances are sensitive to the pore structure of cathodes [22]. Au nanoparticles were deposited on the framework as cathode catalyst, as shown in SEM image in Fig. 6a. XPS of the as-deposited Au nanoparticles is shown in Fig. $6 \mathrm{~b}$, which is characterized by a doublet containing binding energy of $84.0 \mathrm{eV}(\mathrm{Au} 4 \mathrm{f} 7 / 2)$ and $87.5 \mathrm{eV}(\mathrm{Au} 4 \mathrm{f5} / 2)$. The two peaks have a binding energy difference of $3.5 \mathrm{eV}$ and a peak area ratio of 4:3, which corresponds to the characteristics of $\mathrm{Au}(0)$ [23]. We have studied the electrochemical active areas of the foam, which can reflect the amount of active sites in electrochemical processes more veritably compared with the BET surface areas. In comparison with other 
detection protocols, $\mathrm{CV}$ of electroactive species in a conducting aqueous solution is a valuable means of probing the electrochemical characterization of the nonstandard electrode [24]. The Au modified porous foam was electrochemically characterized by $\mathrm{CV}$ in $0.5 \mathrm{~mol} \mathrm{dm}^{-3} \mathrm{H}_{2} \mathrm{SO}_{4}$. The Au nanoaprticles coated raw Ti plate with the same geometric surface area was also characterized under the same conditions for comparison (Fig. S3). The CV curves show that the porous foam has a significant larger $\mathrm{CV}$ area compared with raw Ti plates, indicating the porous foam has a much larger effective surface area due to the porous morphology. Assuming that a specific charge of $386 \mu \mathrm{C} \mathrm{cm}^{-2}$ is required for gold oxide reduction [25,26], the porous foam has a total active surface of $5.6 \mathrm{~cm}^{2}$, while the value of raw Ti plate is very small. The significant enhancement represents a much larger electrochemical active area of the porous foam.

\section{Fig. 7.}

The electrochemical properties of LOBs are shown in Fig. 7, in which, capacities are all calculated based on the mass of Au catalyst. Fig. 7a presents discharge/charge curves of the batteries (at a current density of $0.2 \mathrm{~A} \mathrm{~g}^{-1}\left(0.2 \mathrm{~mA} \mathrm{~cm}{ }^{-2}\right)$ in the potential range of $2.0-4.2 \mathrm{~V}$ ) based on the foam obtained from four temperatures. It can be found that the foam from $650{ }^{\circ} \mathrm{C}$ has the best discharge/charge properties. The battery on the sample from $650{ }^{\circ} \mathrm{C}$ can release a capacity of more than $15000 \mathrm{mAh} \mathrm{g}^{-1}$, while the other batteries release no more than $4000 \mathrm{mAh} \mathrm{g}^{-1}$. We consider the widespread pores in $\mathrm{Ti}$ foam are responsible for ultrahigh capacity on the sample of $650{ }^{\circ} \mathrm{C}$, as shown in Fig. 2e and f. Owing to porous structure of the sample from $750{ }^{\circ} \mathrm{C}$ (Fig. 2c), 
the battery exhibits more capacity (3800 $\mathrm{mAh} \mathrm{g}^{-1}$ ) than the other two batteries (around $2000 \mathrm{mAh} \mathrm{g}^{-1}$ on the samples from 550 and $800{ }^{\circ} \mathrm{C}$ ).

\section{Fig. 8.}

\section{Fig. 9.}

Discharge/charge curves of the battery (based on $\mathrm{Ti}$ foam from $650{ }^{\circ} \mathrm{C}$ ) at different rate current densities within same capacity limitation can describe the variation of overpotentials with discharge/charge currents, as shown in Fig. 7b. The battery has a discharge potential of $2.5 \mathrm{~V}$ (vs. $\mathrm{Li}^{+} / \mathrm{Li}$, similarly hereinafter) and a charge potential of $3.2 \mathrm{~V}$ at a current density of $\left.1.0 \mathrm{~A} \mathrm{~g}^{-1}(1.0 \mathrm{~mA} \mathrm{~cm})^{-2}\right)$ within a capacity limitation of $1000 \mathrm{mAh} \mathrm{g}^{-1}$. The overpotentials increase with the rate current rising slightly, that the charge potential maintains around $3.6 \mathrm{~V}$ at a current density of $2.0 \mathrm{~A} \mathrm{~g}^{-1}\left(2.0 \mathrm{~mA} \mathrm{~cm}{ }^{-2}\right)$. The cycle performance of the battery was studied at $2.0 \mathrm{~A}$ $\mathrm{g}^{-1}$, as shown in Fig. 7c, $\mathrm{d}$ and e. Fig. $7 \mathrm{~d}$ and e show the momentary potential depending on running time and the end potentials of discharge/charge processes depending on cycle number, respectively. We can see that the battery can maintain near 120 cycles at $2.0 \mathrm{~A} \mathrm{~g}^{-1}$ before sudden death. The electrochemical behavior during the 1-20 and 20-30 cycles are shown in Fig. S4, including discharge/charge curves and time dependent potential variation curves. Obviously, the overpotentials increase sharply in the initial 20 cycles (Fig. S4a and b), especially the charge overpotential. Then, they maintains well after the 20th cycle, as shown in Fig. S4c and d. Discharge/charge curves of the 10th, 50th, and 100th cycles in Fig. 7f exhibit similar patterns, revealing consistent cathode processes in cycling. SEM test of the foam after 
cycling was carried out to investigate the stability of porous frameworks. As seen from Fig. 8a, a layer of undecomposed discharge product deposits on the foam. The pore structure remains well in the foam, as shown in Fig. 8b and c. Therefore, tough framework and stable composition of the cathodes are responsible for the good cycle performance. The kinetics of oxygen transport in cathodes at different stage can be measured by EIS, as shown in Fig. 9a. The Nyquist plots of as-assembled battery and after cycling almost have the same patterns, indicating good recovering ability of the cathodes. However, the undecomposed precipitate grows continuously on the catalyst in a long cycle test, causing the resistance of electrochemical reaction (semicircles) increasing. Accordingly, the radius of semi-circle in Nyquist plot is larger than pristine state, as shown in Fig. 9a. Furthermore, the diffusion coefficients of oxygen at the two stages are calculated from Fig. $9 b$ and Equation 1, 2 and 3 [27]:

$\sigma=\left[\frac{R T}{\sqrt{2} n^{2} F^{2} A C_{O_{2}}}\right] \frac{1}{\sqrt{D_{O_{2}}}}$,

converted to

$$
D=\frac{R^{2} T^{2}}{2 n^{4} F^{4} A^{2} \sigma^{2} C_{O 2}^{2}},
$$

where the meanings of $n$ is the number of electrons per-molecule during $\mathrm{O}_{2}$ reaction, $A$ is the surface area of the anode, $D$ is the diffusion coefficient of $\mathrm{O}_{2}, R$ is the gas constant, $T$ is the absolute temperature, $F$ is the Faraday constant, $C$ is the concentration of lithium ion, and $\sigma$ is the Warburg factor which has relationship with $Z_{r e}$ :

$$
Z_{r e}=R_{D}+R_{L}+\sigma \omega^{-1 / 2}
$$


Acknowledgments

This work was supported by the National Science Foundation of China (NSFC) (NO. 21203044) and Fundamental Research Funds for the Central Universities (HIT. IBRSEM. A. 201407).

\section{References}

[1]. J. Banhart, Prog. Mater. Sci. 46 (2001) 559-632.

[2]. J. Biener, G.W. Nyce, A.M. Hodge, M.M. Biener, A.V. Hamza, S.A. Maier, Adv. Mater. 20 (2008) 1211-1217.

[3]. Y. Li, Y.-Y. Song, C. Yang, X.-H. Xia, Electrochem. Commun. 9 (2007) 981-988.

[4]. C. Xu, B.M. Gallant, P.U. Wunderlich, T. Lohmann, J.R. Greer, ACS Nano 9 (2015) 5876-5883.

[5]. Z. Qi, U. Vainio, A. Kornowski, M. Ritter, H. Weller, H. Jin, J. Weissmüller, Adv. Funct. Mater. 25 (2015) 2530-2536.

[6]. X. Niu, M. Lan, H. Zhao, C. Chen, Chem-Eur J. 19 (2013) 9534-9541.

[7]. J. Jina, G. Zheng, Y. Ge, S. Deng, W. Liu, G. Hui, Electrochimica Acta 153 (2015) 594-601.

[8]. S.Y. Oh, R. Selvaraj, Y. Kim, J. Ind. Eng. Chem. 26 (2015) 95-99.

[9]. X.W. Lou, D. Deng, J.Y. Lee, J. Feng, L.A. Archer, Adv. Mater. 20 (2008) $258-262$.

[10]. Y. Xia, W.T. Ng, H.B. Wu, X. Wang, X.W. (David) Lou, Angew. Chem. Int. Ed. 51 (2012) 7213-7216. 
[11]. Z. Peng, S.A. Freunberger, Y. Chen, P.G. Bruce, Science 337 (2012) $563-566$.

[12]. G.-W. Yang, C.-L. Xu, H.-L. Li, Chem. Commun. (2008) 6537-6539.

[13]. H. Huo, Y. Zhao, C. Xu, J. Mater. Chem. A 2 (2014) 15111-15117.

[14]. M. Long, H.J. Rack, Biomaterials 19 (1998) 1621-1639.

[15]. S.-W. Yook, B.-H. Yoon, H.-E. Kima, Y.-H. Koh, Y.-S. Kim, Mater. Lett. 62 (2008) 4506-4508.

[16]. G. Zhao, R. Mo, B. Wang, L. Zhang, K. Sun, Chem. Mater. 26 (2014) $2551-2556$.

[17]. G. Zhao, Y. Niu, L. Zhang, K. Sun, J. Power Sources 270 (2014) 380-390.

[18]. Y. Qiao, S.-J. Bao, C. M. Li, X.-Q. Cui, Z.-S. Lu, J. Guo, ACS Nano 2 (2008) $113-119$.

[19]. M. Tian, G. Wu, A. Chen, ACS Catal. 2 (2012) 425-432.

[20]. Y. Fu, Z.D. Wei, S.G. Chen, L. Li, Y.C. Feng, Y.Q. Wang, X.L. Ma, M.J. Liao, P.K. Shen, S.P. Jiang, J. Power Sources 189 (2009) 982-987.

[21]. F. Czerwinski, Magnesium Alloys Properties: in Solid and Liquid States AvE4EvA, 2014.

[22]. J. Xiao, D.H. Wang, W. Xu, D.Y. Wang, R.E. Williford, J. Liu, J.G. Zhang, J. Electrochem. Soc. 157 (2010) A487-A492.

[23]. I. Lopez-Salido, D.C. Lim, R. Dietsche, N. Bertram, Y.D. Kim, J. Phys. Chem. B 110 (2006) 1128-1136. 
[24]. M.D. Porter, T.B. Bright, D.L. Allara, C.E.D. Chidsey, J. Am. Chem. Soc. 109 (1987) 3559-3568.

[25]. R. Szamocki, A. Velichko, C. Holzapfel, F. Mucklich, S. Ravaine, P. Garrigue, N. Sojic, R. Hempelmann, A. Kuhn, Anal. Chem. 79 (2007) 533-599.

[26]. K. Hu, D. Lan, X. Li, S. Zhang, Anal. Chem. 80 (2008) 9124-9130.

[27]. A.J. Bard, L.R. Faulkner, Electrochemical Methods, Wiley New York, 1980 $213-214$.

[28]. S.T. Kim, N.-S. Choi, S. Park, J. Cho, Adv. Energy Mater. 2015, 5, DOI: 10.1002/aenm.201401030.

[29]. M.M.O. Thotiyl, S.A. Freunberger, Z. Peng, P.G. Bruce, J. Am. Chem. Soc. 135 (2013) 494-500.

[30]. E. Nasybulin, W. Xu, M. H. Engelhard, Z. Nie, X. S. Li, J.-G. Zhang, J. Power Sources 243 (2013) 899-907. 


\section{Figure Captions :}

Fig. 1. XRD patterns of raw $\mathrm{Ti}$ foam, Ti foam heat-treated with $\mathrm{Mg}$ and the foam after dissolving $\mathrm{Mg}$ in acid.

Fig. 2. SEM images of $\mathrm{Ti}$ foam corroded by molten $\mathrm{Mg}$ at different temperatures: (a) 550, (b) 650, (c) 750, and (d) $800{ }^{\circ} \mathrm{C}$; (e, f) images with different magnifications of the samples obtained at $650{ }^{\circ} \mathrm{C}$.

Scheme 1. Schematic diagram of preparing porous Ti foam.

Fig. 3. TEM images of pore walls scraped from the samples prepared at $650^{\circ} \mathrm{C}$ : (a) image in low magnification, $(\mathrm{b}, \mathrm{c})$ HRTEM images of selected areas in (a), inset in (a) is SAED pattern of the walls.

Fig. 4. SEM images of Ti foam corroded by molten $\mathrm{Mg}$ at $650{ }^{\circ} \mathrm{C}$ for different times: (a) 1, (b) 3, (c) 6, and (d) $12 \mathrm{~h}$.

Fig. 5. Adsorption/desorption isotherms (a, b) and pore distribution curves (c, d) of raw Ti foam and porous Ti foam.

Fig. 6. SEM (a) image and XPS (b) pattern of Au nanoparticles deposited by cool spurting.

Fig. 7. Electrochemical properties of the LOBs with porous Ti foam as cathode support. (a) discharge/charge curves of the batteries on Ti foam corroded at different temperatures. (b-f) battery performances on $\mathrm{Ti}$ foam corroded at $650{ }^{\circ} \mathrm{C}$ : (b) discharge/charge curves at 1 and $2 \mathrm{~A} \mathrm{~g}^{-1}$; (c) cycle performance at 2 $\mathrm{A} \mathrm{g}^{-1}$ within a capacity limitation of $1000 \mathrm{mAh} \mathrm{g}^{-1}$; (d) momentary potential depending on running time of the cycling test; (e) end potentials of 
discharge/charge processes depending on cycle number; (f) discharge/charge curves of the 10th, 50th, and 100th cycles.

Fig. 8. SEM images of the porous Ti foam after cycling test.

Fig. 9. Impedance study of porous $\mathrm{Ti}$ cathodes at the stages of pristine battery and after cycle test: (a) Nyquist plots; (b) the relationships between $Z_{\mathrm{re}}$ and $\omega^{-1 / 2}$ at low-frequency region. 
Figures:

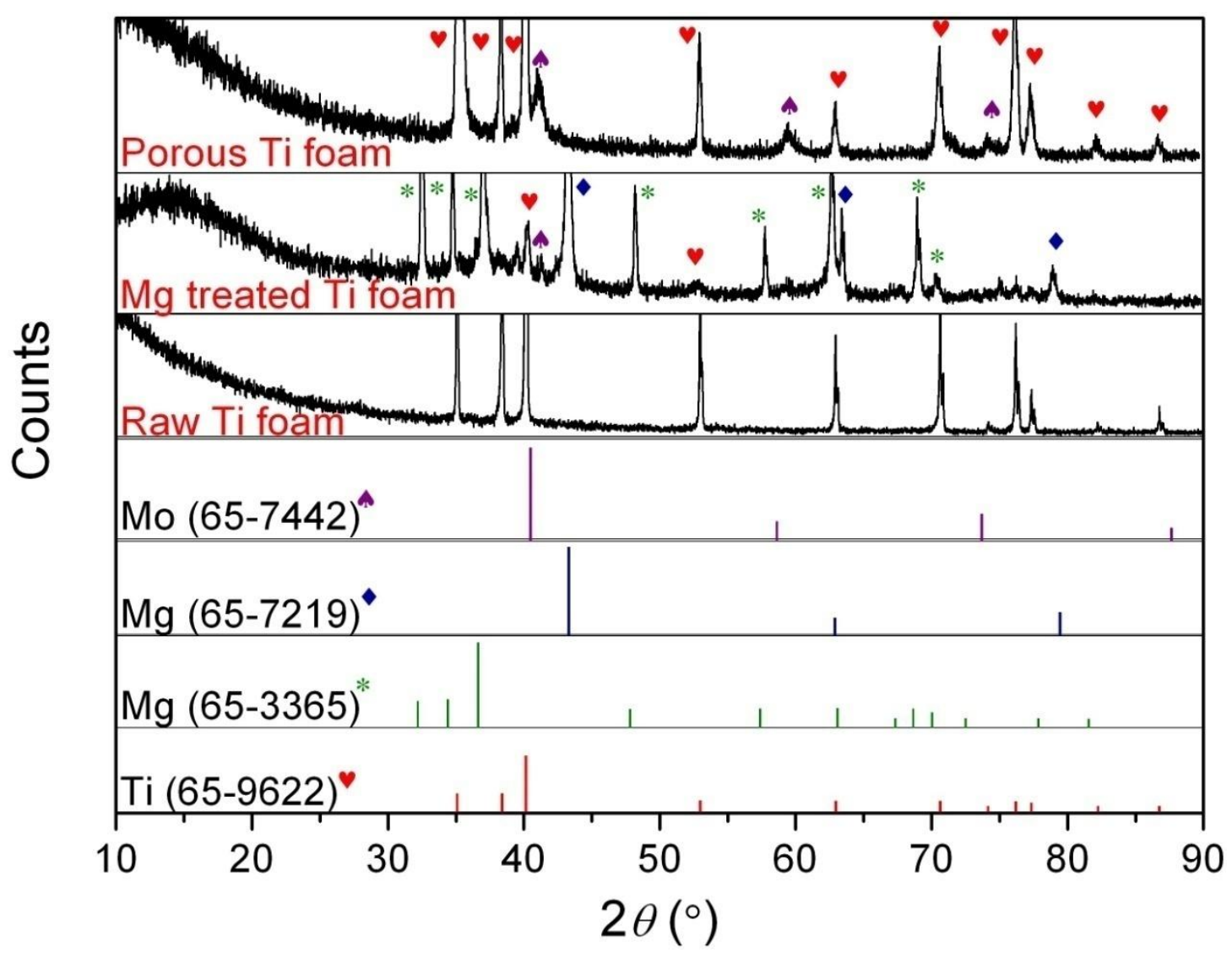

Fig. 1 


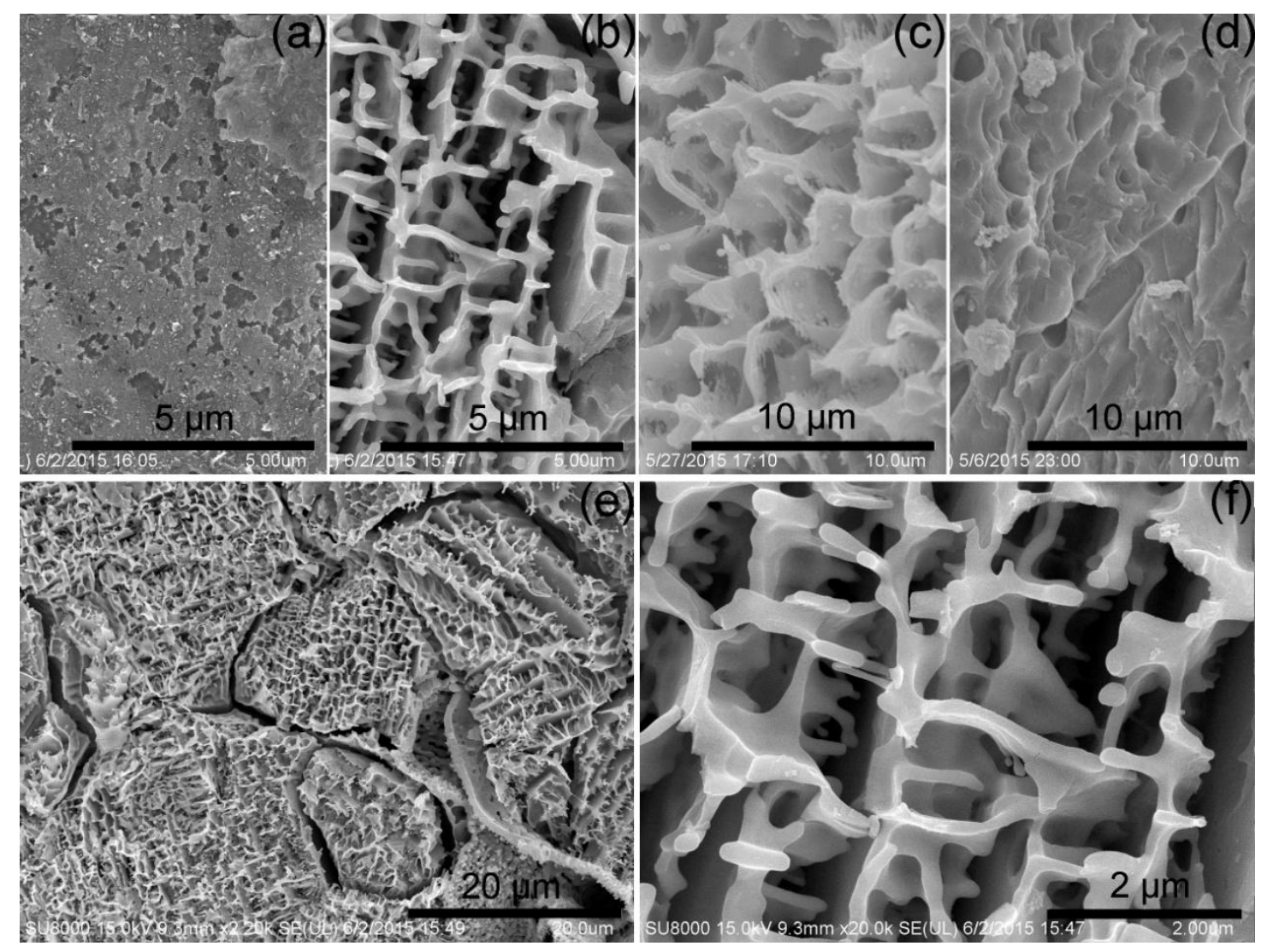

Fig. 2 


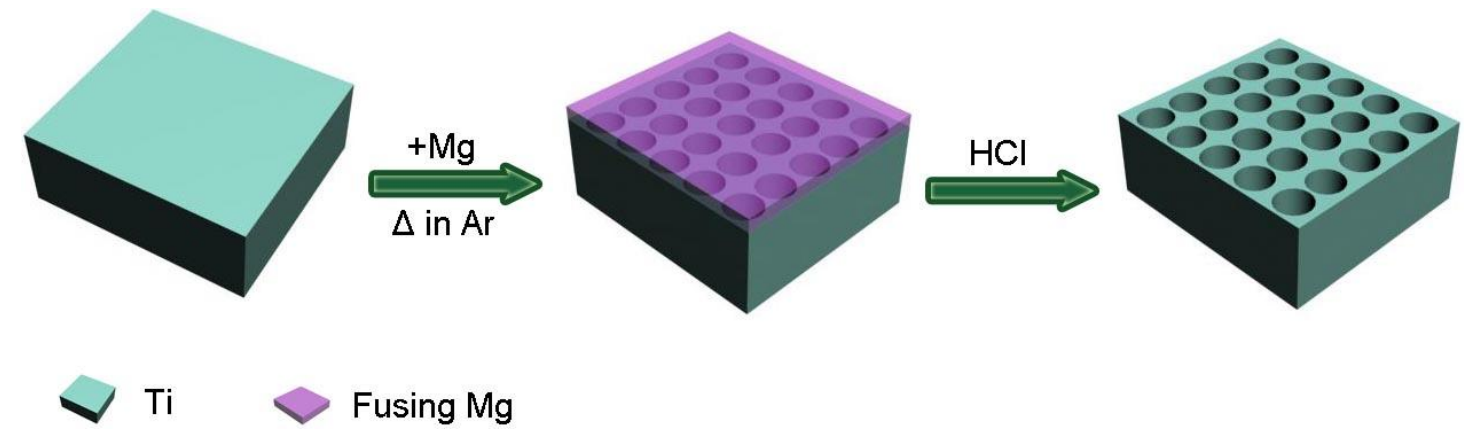

Scheme 1 


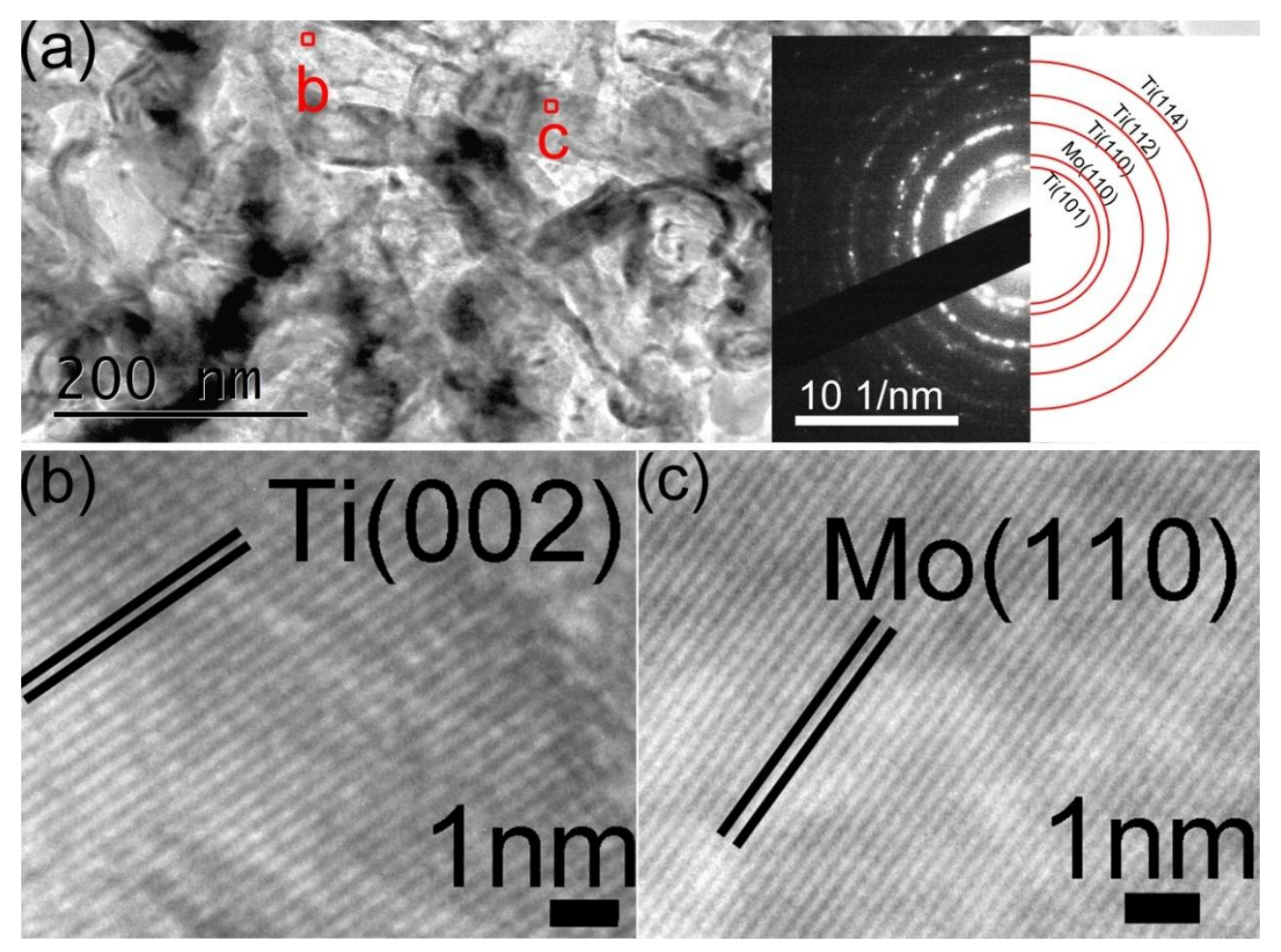

Fig. 3 

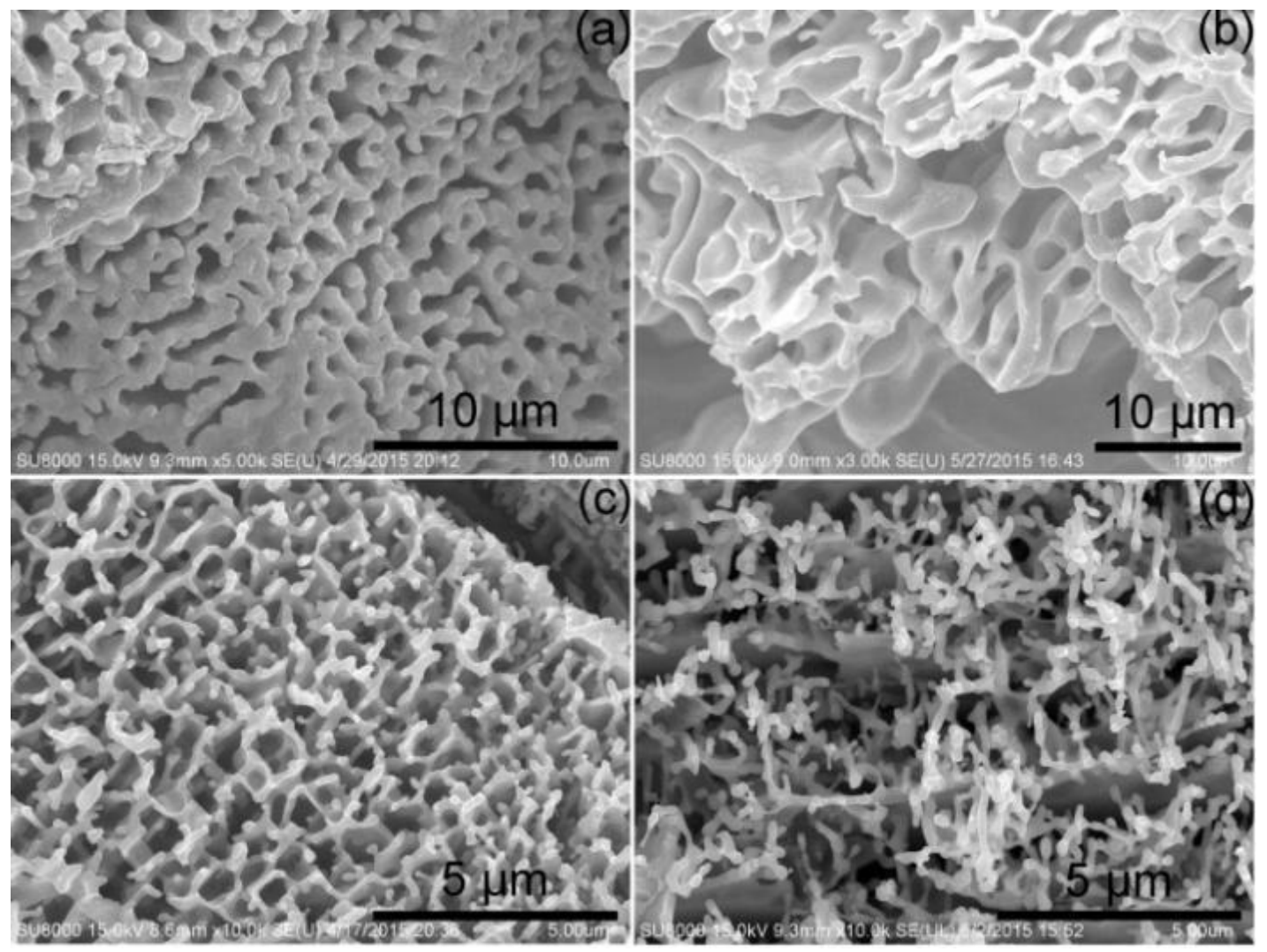

Fig. 4 
(a)

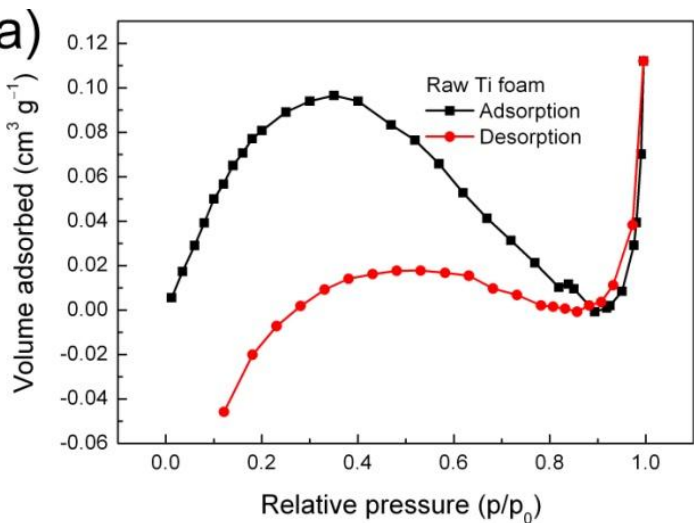

(c)

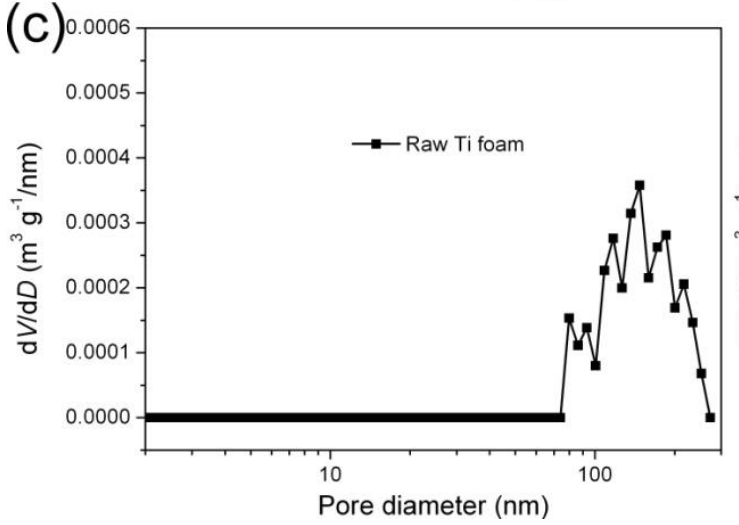

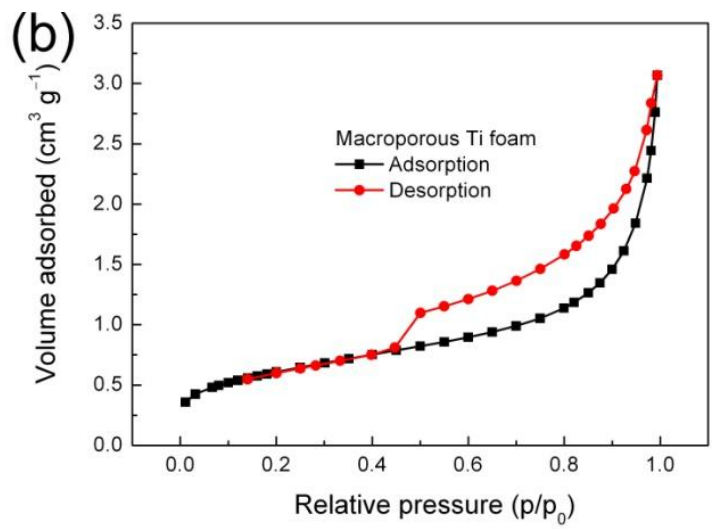

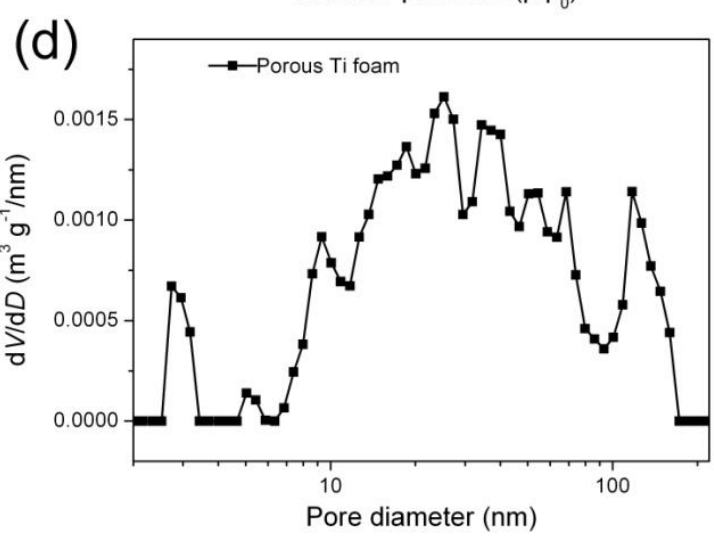

Fig. 5 

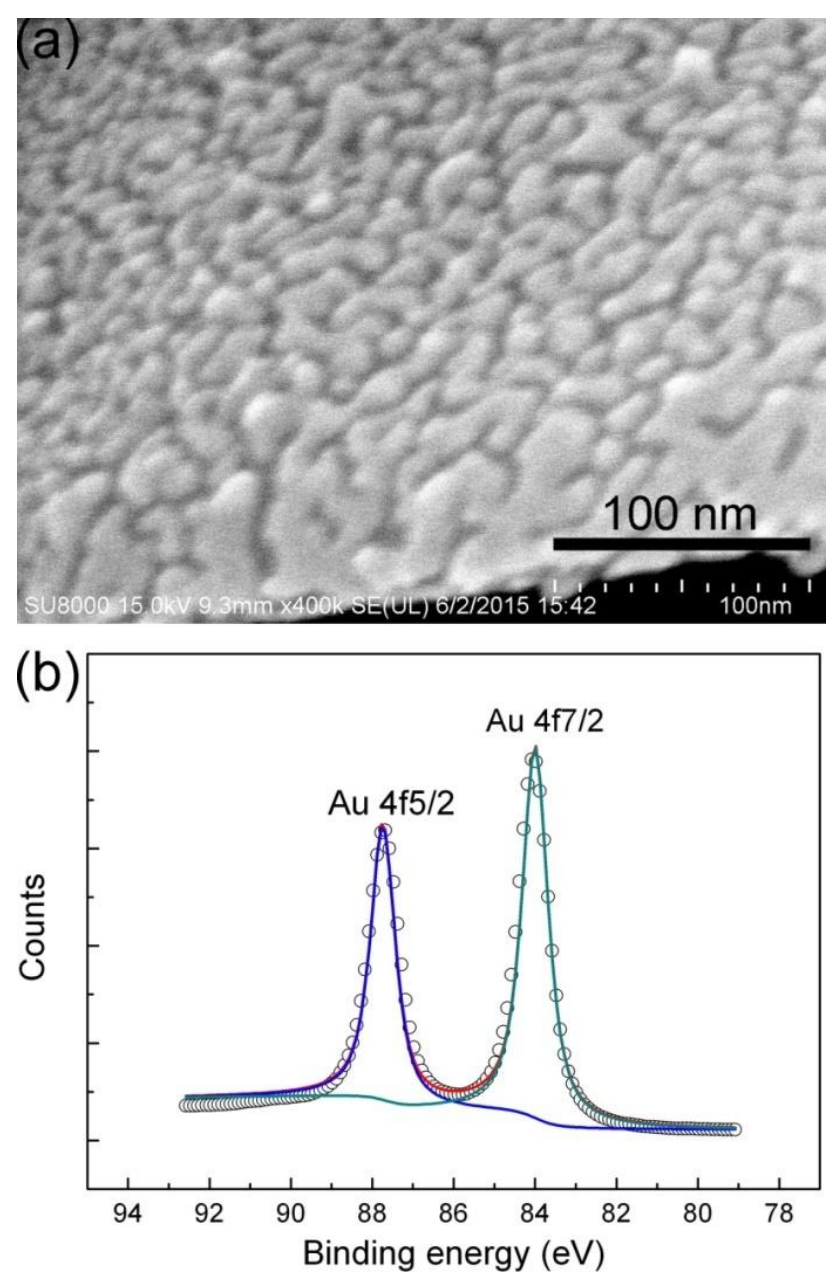

Fig. 6 

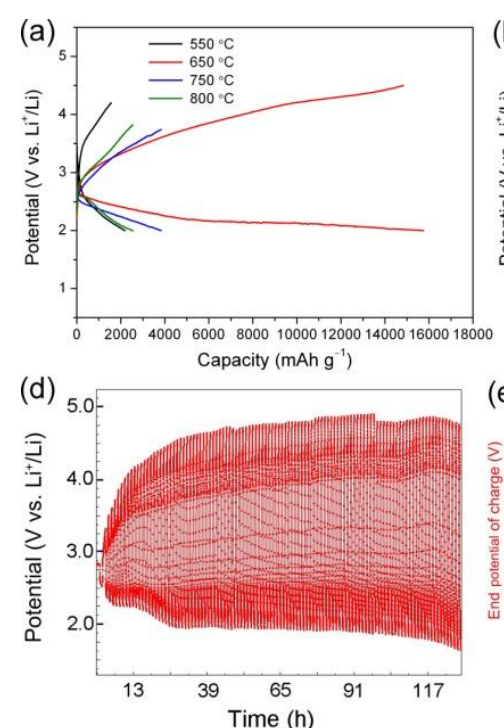

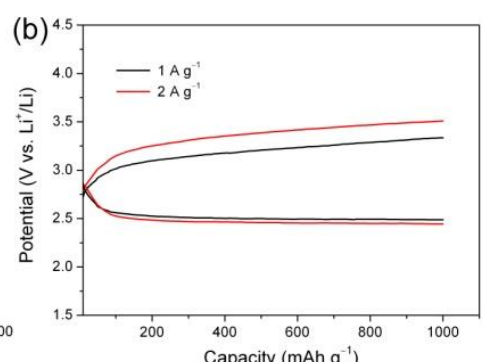

(e)

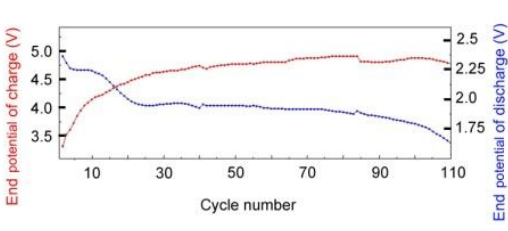

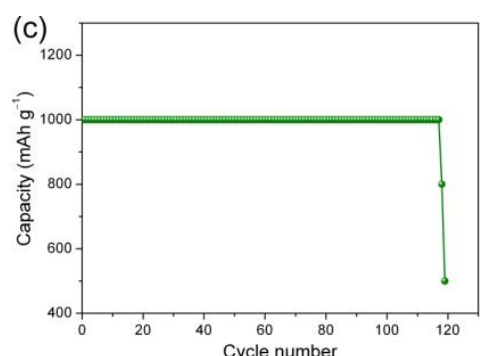

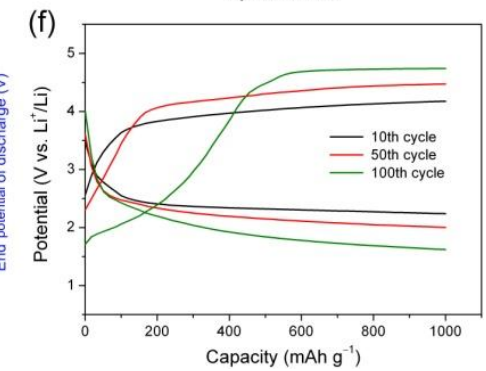

Fig. 7 


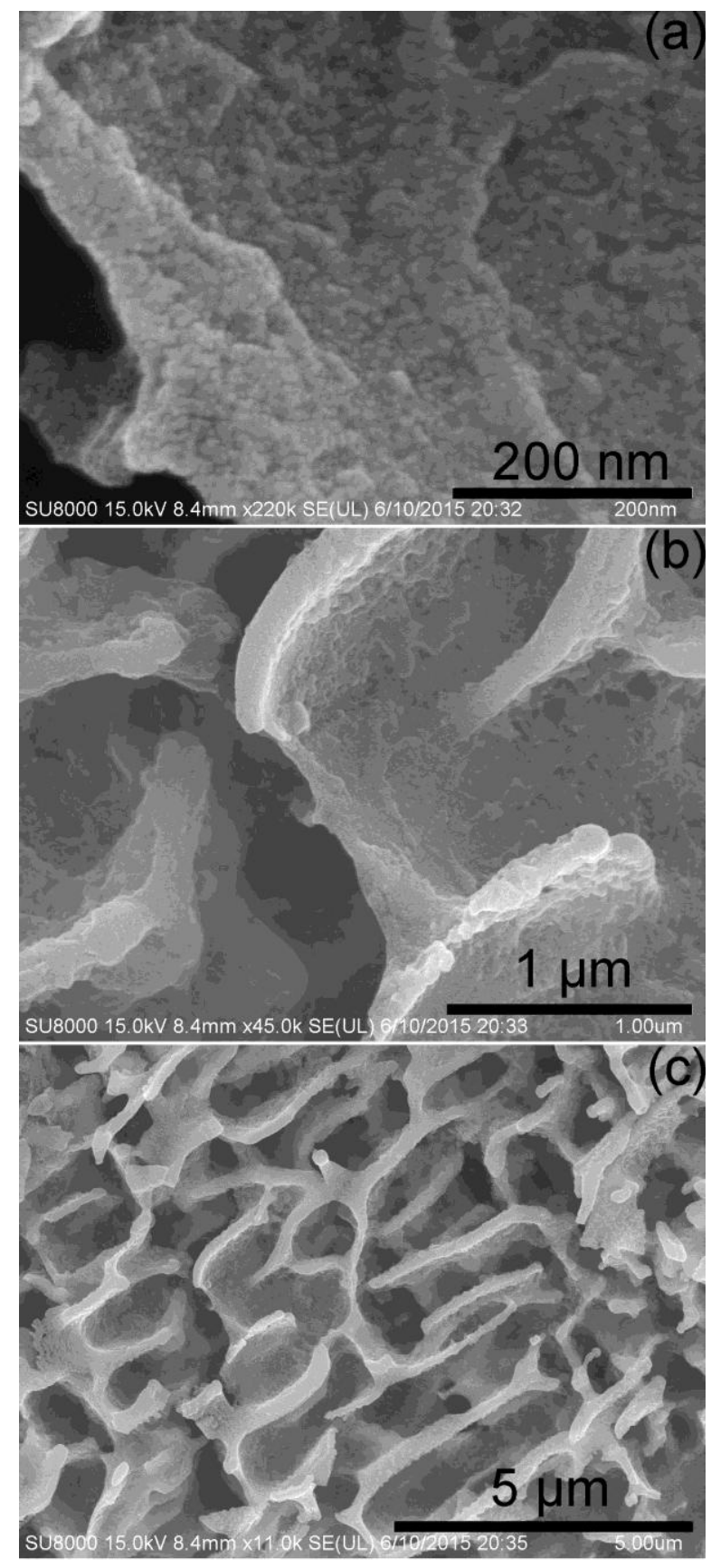

Fig. 8 

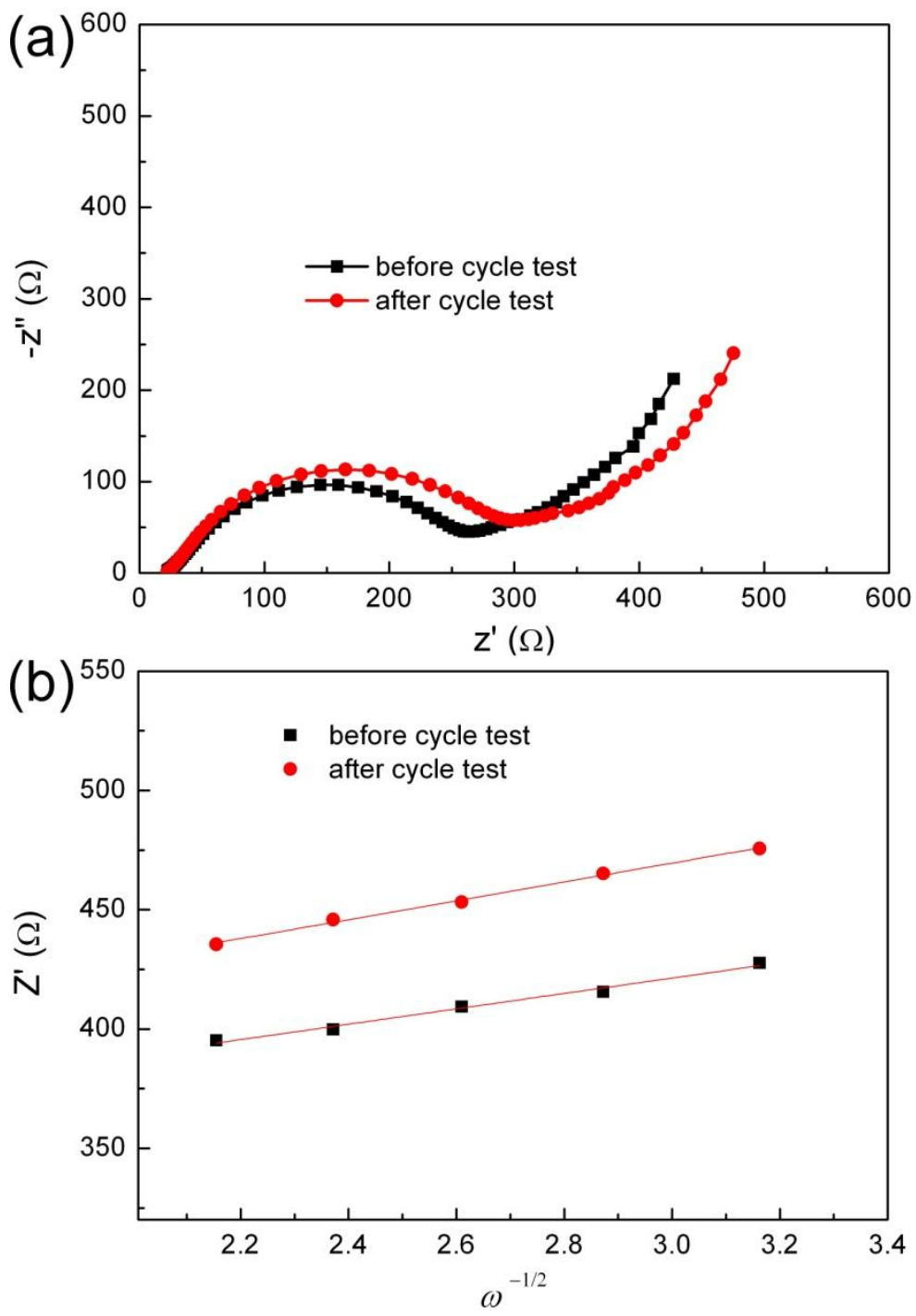

Fig. 9 
Graphical abstract:

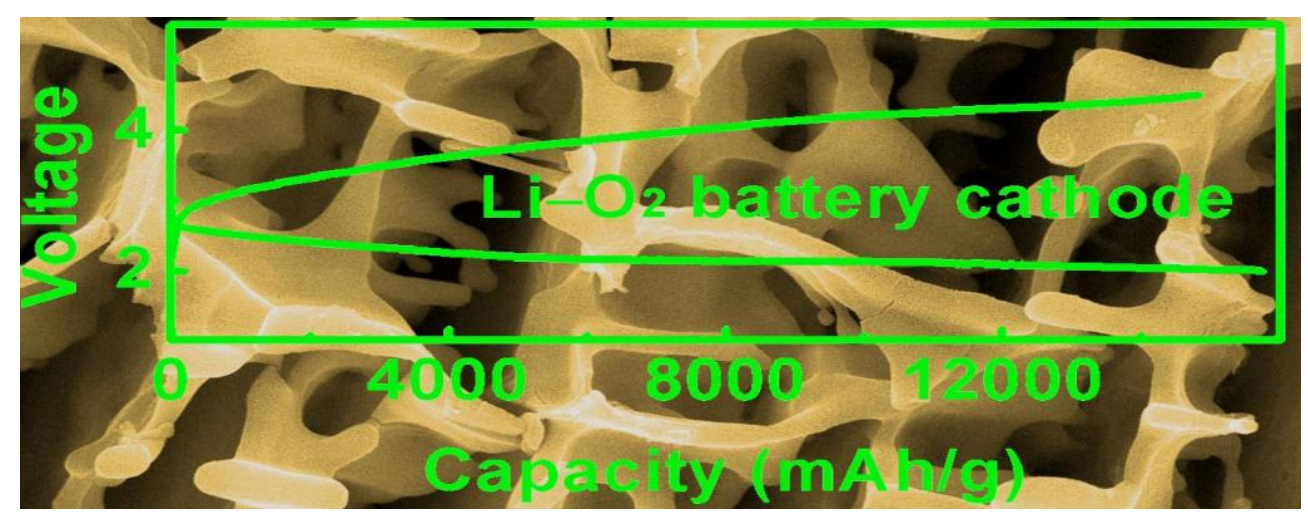

